\title{
The effects of disposition, situation, and setting on in-group favoritism
}

\author{
DANIEL L. WANN \\ Murray State University, Murray, Kentucky \\ and \\ KENNETH A. WEAVER and STEPHEN F. DAVIS \\ Emporia State University, Emporia, Kansas
}

\begin{abstract}
This experiment investigated the differential effects of dispositional (gender) and situational (armband) group membership on in-group favoritism. Subjects met a confederate either similar or dissimilar in disposition and/or situation in an interpersonal setting. The proximity between the subject and the confederate, as well as the subject's memory about the confederate, were the dependent measures. In addition, the ecological validity of studies that employ hypothetical situations in their methodology was examined. The results indicated that similarity of both disposition and situation resulted in the highest levels of favoritism. Memberships based on disposition, as compared with situation, resulted in greater favoritism. The results also demonstrated the need for ecological validity in research, as significant differences were found between actual and hypothetical settings.
\end{abstract}

Research has demonstrated that people tend to favor members of their own group over members of out groups. This in-group-favoritism effect has been demonstrated in a variety of settings. For example, individuals favor members of the in-group in their allocation of rewards (Tajfel, Billig, Bundy, \& Flament, 1971), social evaluations (Gerald \& Hoyt, 1974), expectancies for favorable behaviors (Howard \& Rothbart, 1980), and helping behavior (Piliavin, Dovidio, Gaertner, \& Clark, 1981). Certainly individuals belong to many different groups, and these groups may be categorized as having either a dispositional or situational style.

Dispositional group memberships are based on stable, internal characteristics such as gender or race (Berger, Gardner, Parks, Schulman, \& Miller, 1976). Conversely, situational group memberships are formed around temporary and often external factors such as random assignment to the group or clothing (Allen \& Wilder, 1975; Yener, 1982). However, the relative strength of these two categories in determining in-group favoritism has not been investigated. That is, the more powerful factor in establishing the in-group bias is unknown, although a combination of both dispositional and situational characteristics would most likely result in the greatest amount of in-group favoritism. Therefore, one purpose of the current investigation was to determine the membership style that accounts for the greatest proportion of in-group favoritism.

The authors wish to thank Loren D. Tompkins and William E. Thompson for their valuable input during the execution of this research. Requests for reprints may be addressed to D. L. Wann, Department of Psychology, Murray State University, Murray, KY 42071.
A second focus of this research was on the ecological validity of research in social and cognitive psychology (Neisser, 1976). While a large portion of psychological research involves hypothetical settings (e.g., Becker, Gield, \& Froggatt, 1983; Noffsinger, Pellegrini, \& Burnell, 1983), the question of generalizing the results to actual settings exists. Although psychologists need not concern themselves with mundane realism (Aronson, Brewer, \& Carlsmith, 1985), they do need to ensure that their research is experimentally real, that similar results would be obtained in actual settings. In fact, this issue has received a great deal of recent attention, as indicated by an article in the American Psychologist (Gruneberg, Morris, \& Sykes, 1991). Therefore, in addition to reviewing the relative strength of different group-membership variables, the current investigation also examined the ecological validity of such research.

\section{METHOD}

\begin{abstract}
Subjects and Design
One hundred sixty college-student volunteers ( 80 of each gender, $M$ age $=19.7$ years) participated in exchange for extra credit in their introductory psychology or sociology course. The design was a 2 (subject gender: male or female) $\times 2$ (confederate gender: male or female) $\times 2$ (situational group membership: in group or out group) $\times 2$ (setting: actual or hypothetical) between-subject factorial. The subjects were blocked on gender and randomly assigned to one of the eight treatment conditions.
\end{abstract}

\section{Procedure \\ Actual setting. The subjects in the actual-setting condition were tested in groups of 15 to 25 individuals and asked to report to a predetermined room. Upon arrival and after completing a consent statement, the sub- jects were randomly assigned to either the "blue" group or the "red" group. These groups served as the situational-group-membership dimen- sion. Each subject was asked to wear a blue or red armband around}


his/her right arm, thus making this membership public as well as salient. The subjects were then escorted to a second room, where they were seated in circles according to their situational group membership. Both the blue and red groups then completed a group-cohesion task with a group member randomly chosen to be the recorder. This task required that the subjects answer such questions as "Which group member most recently visited the library?" and was designed to promote group identity. The subjects were also informed that, at 90-sec intervals, they would be asked to proceed individually to a third room, enter it, sit down, and wait for further instructions.

After all questions were answered, and as the groups began to complete the cohesion task, the subjects were randomly selected to move to the third room. This room contained seven chairs placed in a fan shape so as to be equidistant ( $6 \mathrm{ft}$ ) from the entrance. When the subjects arrived, they found a 21-year-old male or female confederate seated in the sixth chair from the door. The gender of the subject and confederate was used as the criterion for dispositional group membership (i.e., male group or female group). In addition, the confederates wore either a similarly or dissimilarly colored armband. Thus, the confederate was either similar or dissimilar in the dispositional- and/or situational-group-membership variables, resulting in four possible group-membership combinations: similar disposition and similar situation (SDSS), similar disposition and dissimilar situation (SDDS), dissimilar disposition and similar situation (DDSS), or dissimilar disposition and dissimilar situation (DDDS).

As the subjects entered the room, the confederate smiled naturally and established eye contact but did not speak to them. When a subject sat down, the confederate recorded the number of chairs separating $\mathrm{him} /$ herself from the subject. This measure of proximity (Hare, 1962; Rosenfeld, 1965) was employed as the first dependent variable. Less interpersonal distance separating the subject and the confederate was indicative of in-group favoritism. Once the seating was recorded, the confederate asked the subject to move to a fourth room, where he/she completed a 10-item test that assessed his/her memory for both dispositional and situational characteristics of the confederate. Scores on this measure served as the second dependent variable. In addition to the proximity of the subject to the confederate, a great deal of information concerning the differential effects of situation and disposition on favoritism could be acquired from an understanding of the characteristics to which individuals attended. Once the subject had finished the memory test, he/she was asked to move to a fifth and final room for debriefing on the true nature and hypotheses of the experiment.

Hypothetical setting. The procedure for the subjects in the imaginary condition was identical except that after receiving and donning the armbands and being seated according to group, these subjects were given a sheet of paper that contained a diagram of the third room (i.e., the room containing the chairs and the confederate) and a typed description of the testing situation. Each subject was instructed to read the description carefully and then circle the chair in which he/she would sit. Once the diagrams had been completed and collected, the subjects were sent to a separate room for debriefing.

\section{RESULTS}

To test the hypothesis that the greatest degree of ingroup favoritism would be found when the subjects and confederate were members of the same dispositional and situational groups, the subjects were collapsed into four conditions of group membership: SDSS, SDDS, DDSS, and DDDS. A one-way analysis of variance (ANOVA) supported the prediction $[F(3,156)=3.71, p<.05]$. According to Newman-Keuls post hoc comparisons, the subjects in the SDSS condition sat significantly closer to the confederate $(M=.60$ chairs) than did the subjects in the SDDS $(M=1.02)$, DDSS $(M=1.13)$, and DDDS $(M=1.13)$ conditions, which did not differ. Trend analyses indicated a significant linear trend $[F(1,156)=8.56$, $p<.01]$, but the quadratic trend did not attain significance $[F(1,156)=2.67, p>.10]$.

To examine the differential impact of dispositional and situational group memberships on in-group favoritism, and to review the impact of ecological validity on experiments that investigate in-group bias, the proximity measure was analyzed using a 2 (subject gender: male or female) $\times 2$ (confederate gender: male or female) $\times 2$ (situational group membership: in group or out group) $\times 2$ (setting: actual or hypothetical) between-subject ANOVA. No significant main effects emerged, although the armband (i.e., situational) variable approached significance $[F(1,143)=$ $3.11, p=.08]$. The subjects tended to sit closer to the situational in-group confederate $(M=.87)$ than to the outgroup confederate $(M=.98)$. The two-way subject gender $\times$ confederate gender interaction was significant $[F(1,143)$ $=6.52, p<.02]$. Consistent with other research on ingroup favoritism (e.g., Gerald \& Hoyt, 1974; Howard \& Rothbart, 1980), the subjects sat closer to members of their own dispositional group $(M=.83$ and .80 chairs for males and females, respectively) than to members of the dispositional out group $(M=1.03$ and 1.08). However, a statistically significant three-way interaction involving subject gender, confederate gender, and setting qualified the aforementioned two-way interaction $[F(1,143)=4.56$, $p<.05]$. As depicted graphically in Figure 1 , the ingroup-favoritism effect was found only in the real setting.

To further explore the differential effects of disposition and situation on favoritism, scores on the memory test for subjects in the actual setting were analyzed using a 2 (subject gender: male or female) $\times 2$ (confederate gender: male or female) $\times 2$ (situational group membership: in group or out group) $\times 2$ (question type: dispositional or situational) mixed-factor analysis of variance. The first three factors were between-subject variables, and the final factor was a within-subject variable. The main effect

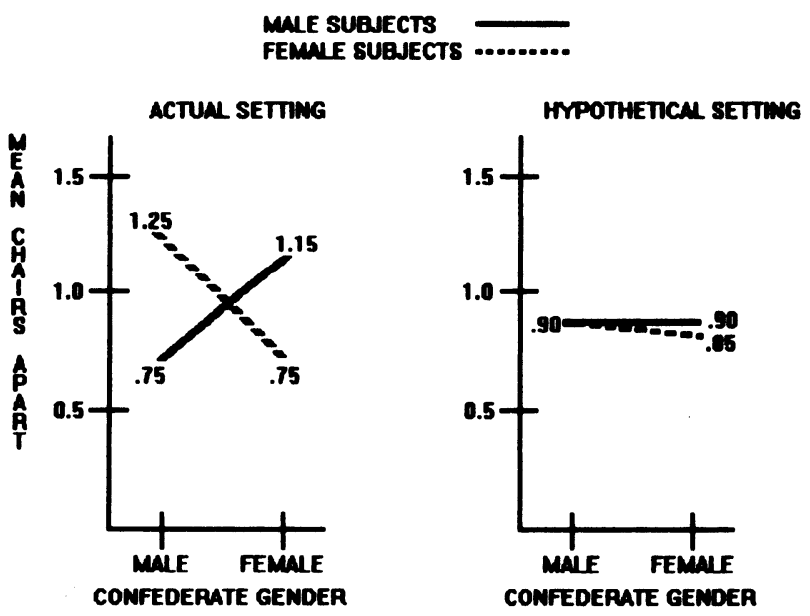

Figure 1. Mean scores for interpersonal proximity by subject gender, confederate gender, and setting. Higher numbers indicate lower levels of in-group favoritism. 
of question type was highly significant $[F(1,144)=69.54$, $p<.0001]$, as the subjects demonstrated better recall of the confederate's dispositional characteristics $(M=4.09)$ than his/her situational characteristics $(M=2.94)$.

\section{DISCUSSION}

As predicted, in-group favoritism was highest when individuals shared both dispositional and situational qualities. Furthermore, on the basis of the results of both the proximity measure and the memory test, it appears that while both factors combined generate the highest levels of in-group bias, individually, memberships based on dispositional variables carry the most weight. This finding is consistent with attributional research in social psychology that explores the fundamental attribution error. This common attributional bias is found when individuals overestimate the importance of dispositional factors in determining the causes of other people's behavior (Ross, 1977). Similarly, our subjects focused on the dispositional traits of the confederate, as indicated by the proximity scores and subjects' memory for these traits.

The current investigation also extends the research on the in-groupfavoritism effect to situations that involve personal space. As reported earlier, individuals favor members of their own groups in a variety of ways. Yet another dimension in which individuals are biased in favor of the in group concerns the amount of personal space they require. Research in this area has found differences in the amount of personal space desired by individuals. For example, adults tend to desire more space than do children, and men maintain greater distances than do women (Hayduk, 1983). On the basis of the present research, in-group membership must be added to this list, thereby furthering understanding of the personal-space phenomenon.

Finally, the results also demonstrate the need for ecological validity in research. A desire for methodologies that are experimentally real should be of utmost concern to researchers investigating in-group favoritism. Research that employs hypothetical settings may mute this powerful effect, leading to invalid and ungeneralizable results.

\section{REFERENCES}

Allen, V., \&ilder, D. A. (1975). Categorization, belief similarity, and intergroup discrimination. Journal of Personality \& Social Psychology, 32, 971-977.
Aronson, E., Brewer, M., \& Carlsmith, J. M. (1985). Experimentation in social psychology. In G. Lindzey \& E. Aronson (Eds.), Handbook of social psychology (Vol. 1, pp. 441-486). Hillsdale, NJ: Erlbaum.

Becker, F. D., Gield, B., \& Froggatt, C. C. (1983). Seating position and impression formation in an office setting. Journal of Environmental Psychology, 3, 253-261.

Berger, C. R., Gardner, R. R., Parks, M. R., Schulman, L., \& MilleR, G. R. (1976). Interpersonal epistemology and interpersonal communication. In G. R. Miller (Ed.), Explorations in interpersonal communication (pp. 149-171). Beverly Hills, CA: Sage.

Gerald, H. B., \& HoYT, M. F. (1974). Distinctiveness of social categorization and attitudes toward in-group members. Journal of Personality \& Social Psychology, 29, 836-842.

Gruneberg, M. M., Morris, P. E., \& SyKes, R. N. (1991). The obituary on everyday memory and its practical applications is premature. American Psychologist, 46, 74-76.

HARE, A. P. (1962). Handbook of small group research. Glencoe, NY: Free Press.

Hayduk, L. A. (1983). Personal space: Where we now stand. Psychological Bulletin, 94, 293-335.

HowARD, J. W., \& RothBART, M. (1980). Social categorization and memory for in-group and out-group behaviors. Journal of Personality \& Social Psychology, 38, 301-310.

NeISSER, U. (1976). Cognition and reality. San Francisco: Freeman. Noffsinger, E. B., Pellegrini, R. J., \& Burnell, G. M. (1983). The effect of associated persons upon the formation and modifiability of first impressions. Journal of Social Psychology, 120, 183-195.

Piliavin, J. A., Dovidio, J. F., Gaertner, S. L., \& Clark, R. D., III (1981). Emergency intervention. New York: Academic Press.

ROSENFELD, H. M. (1965). Effect of an approval-seeking induction on interpersonal proximity. Psychological Reports, 17, 120-122.

Ross, L. (1977). The intuitive psychologist and his shortcomings: Distortions in the attributional process. In L. Berkowitz (Ed.), Advances in experimental social psychology (Vol. 10, pp. 173-220). New York: Academic Press.

Tajfel, H., Billig, M. G., Bundy, R. P., Flament, C. (1971). Social categorization and intergroup behavior. European Journal of Social Psychology, 1, 149-178.

YENER, B. A. (1982). The influence of color on attraction and impression formation. Dissertation Abstracts International, 43, 1809B.

(Manuscript received January 25, 1992.) 